INEEL/CON-2000-00084

PREPRINT

\section{Heat Transfer Enhancement for Finned-Tube Heat Exchangers with Winglets}

\author{
J. E. O'Brien \\ M. S. Sohal
}

November 5, 2000 - November 10, 2000

\section{International Mechanical Engineering Congress and Exposition}

This is a preprint of a paper intended for publication in a journal or proceedings. Since changes may be made before publication, this preprint should not be cited or reproduced without permission of the author.

This document was prepared as a account of work sponsored by an agency of the United States Government. Neither the United States Government nor any agency thereof, or any of their employees, makes any warranty, expressed or implied, or assumes any legal liability or responsibility for any third party's use, or the results of such use, of any information, apparatus, product or process disclosed in this report, or represents that its use by such third party would not infringe privately owned rights. The views expressed in this paper are not necessarily those of the U.S. Government or the sponsoring agency. 


\title{
HEAT TRANSFER ENHANCEMENT FOR FINNED-TUBE HEAT EXCHANGERS WITH WINGLETS
}

\author{
James E. O'Brien and Manohar S. Sohal \\ Idaho National Engineering and Environmental Laboratory \\ Idaho Falls, ID 83415
}

\begin{abstract}
This paper presents the results of an experimental study of forced convection heat transfer in a narrow rectangular duct fitted with a circular tube and/or a delta-winglet pair. The duct was designed to simulate a single passage in a fin-tube heat exchanger. Heat transfer measurements were obtained using a transient technique in which a heated airflow is suddenly introduced to the test section. High-resolution local fin-surface temperature distributions were obtained at several times after initiation of the transient using an imaging infrared camera. Corresponding local fin-surface heat transfer coefficient distributions were then calculated from a locally applied one-dimensional semi-infinite inverse heat conduction model. Heat transfer results were obtained over an airflow rate ranging from $1.51 \times 10^{-3}$ to $14.0 \times 10^{-3} \mathrm{~kg} / \mathrm{s}$. These flow rates correspond to a duct-height Reynolds number range of $670-$ 6300 with a duct height of $1.106 \mathrm{~cm}$ and a duct width-toheight ratio, $\mathrm{W} / \mathrm{H}$, of 11.25 . The test cylinder was sized such that the diameter-to-duct height ratio, $\mathrm{D} / \mathrm{H}$ is 5 . Results presented in this paper reveal visual and quantitative details of local fin-surface heat transfer distributions in the vicinity of a circular tube, a delta-winglet pair, and a combination of a circular tube and a delta-winglet pair. Comparisons of local and average heat transfer distributions for the circular tube with and without winglets are provided. Overall mean finsurface Nusselt-number results indicate a significant level of heat transfer enhancement associated with the deployment of the winglets with the circular cylinder. At the lowest Reynolds numbers (which correspond to the laminar operating conditions of existing geothermal air-cooled condensers), the enhancement level is nearly a factor of two. At higher Reynolds numbers, the enhancement level is close to $50 \%$.
\end{abstract}

\section{INTRODUCTION}

Air-cooled condensers used in binary-cycle geothermal power plants require the use of finned tubes in order to increase heat transfer surface area on the air side. Air is forced through several rows of these finned tubes by large fans. The condenser units can be very large, representing approximately $50 \%$ of the overall capital cost of these plants. In addition, the power required to operate the fans represents a significant parasitic house load, reducing the net power production of the plant. The research presented in this paper has been undertaken with the aim of devising viable heat transfer enhancement strategies for application to geothermal aircooled condensers and similar applications. An effective strategy can result in a reduction in condenser size (and plant capital cost) and/or power consumption.

One heat transfer enhancement strategy that has been studied in some detail is the exploitation of longitudinal vortices to increase heat transfer coefficients with only small increases in pressure-drop penalty. Longitudinal vortices are generated naturally in fin-tube heat exchanger passages by the interaction of the flow with the heat exchanger tube. In this case, the vortices are called horseshoe vortices. Longitudinal vortices can also be created intentionally through the use of winglet vortex generators mounted or punched into the fin surfaces. Jacobi and Shah [1] provide an excellent review of heat transfer enhancement through the use of longitudinal vortices. Various winglet shapes have been studied. Results presented in the present paper are restricted to delta winglets, both as a delta-winglet pair (no tube) and in conjunction with a circular tube. Heat transfer enhancement with double rows of longitudinal vortex-generators (delta-winglet pairs) in a channel flow without tubes has been evaluated experimentally by Tiggelbeck et al. [2]. An investigation of the mechanisms of heat transfer enhancement associated with delta-wing vortex generators was performed by Torii et al. [3]. The specific configuration of vortex generators plus circular tube used in the present study was based on recommendations provided by Fiebig et al. [4]. We are also investigating the usage of oval 

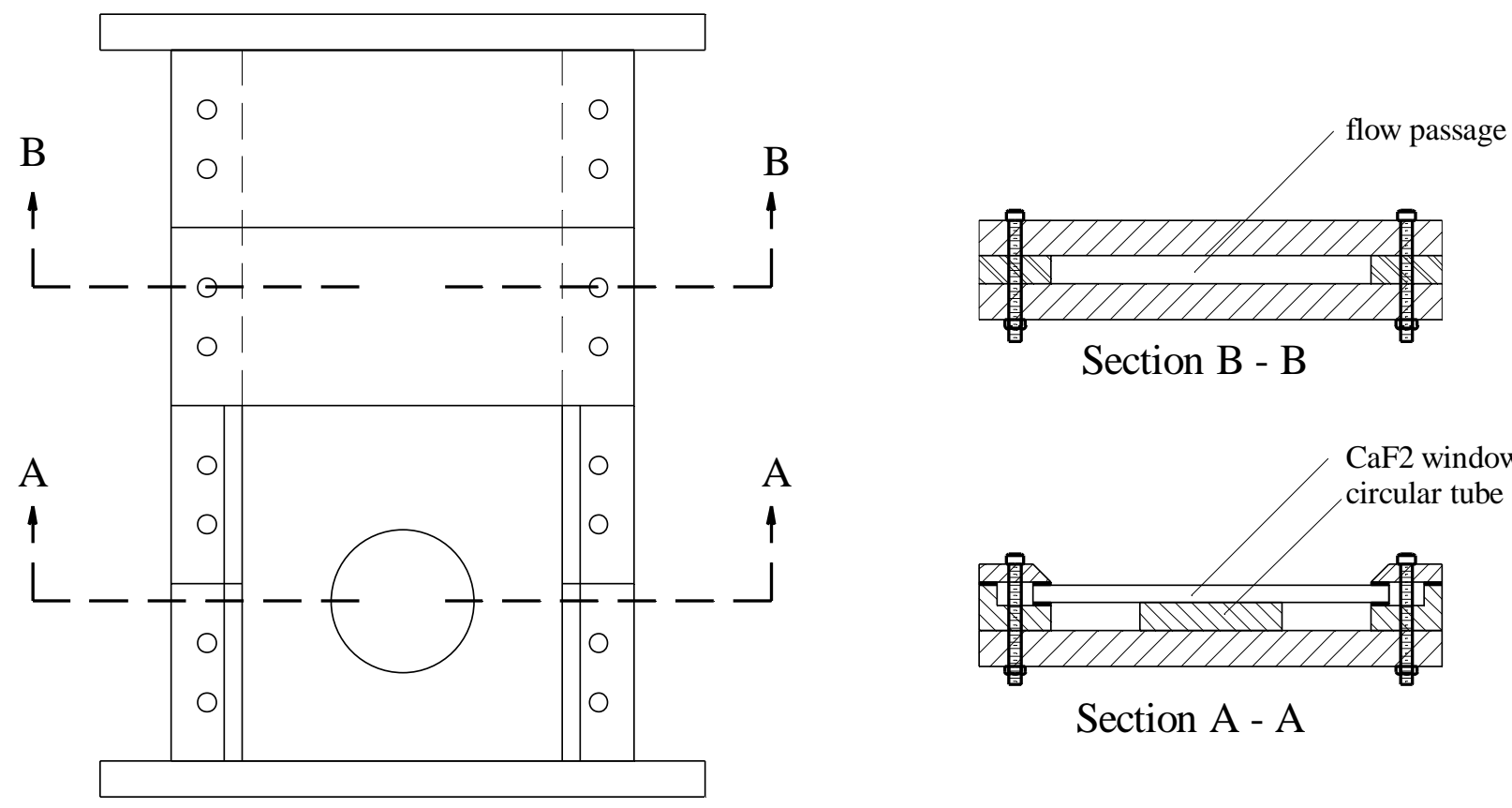

A

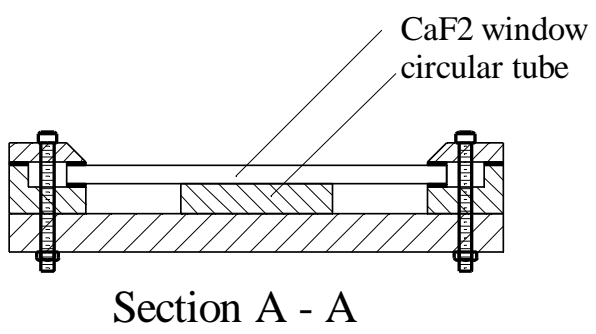

Figure 1. Test section.

tubes instead of circular tubes with or without winglets $[5,6]$ for the geothermal application. Baseline local heat transfer measurements for both circular and oval tubes without winglets were obtained previously by the present authors and are presented in [7].

In order to assess the heat transfer effectiveness of various combinations of tube and vortex-generator geometries, a heat transfer measurement technique that allows for high-resolution visualization and measurement of local heat transfer was chosen for this work. The focus of the work presented in this paper was to document local heat transfer distributions for two cases: a delta-winglet pair with no tube, and a delta-winglet pair positioned in the downstream wake region of a circular tube. During the next phase of the research, delta-winglet vortex generators will be placed in the test section in various configurations with an oval tube. Subsequent research will involve measurement of local heat transfer and pressure drop in single-channel, multiple-tube geometries with winglets. Finally, overall heat transfer and pressure drop will be evaluated for a multiple-channel, multiple-tube-row prototype heat exchangers. Concurrent numerical studies are under way. The numerical studies should allow for evaluation of many more configurations than can be studied experimentally. The ultimate goal is to devise optimal heat exchanger geometries for the geothermal air-cooled condenser application.

\section{NOMENCLATURE}

$\mathrm{D}$

$\mathrm{h}$

$\mathrm{H}$ cylinder diameter, $\mathrm{cm}$

heat transfer coefficient, $\mathrm{W} / \mathrm{m}^{2} \mathrm{~K}$

channel height, $\mathrm{cm}$ $\mathrm{k}$

$\mathrm{L}$

$\dot{m}$

$\mathrm{Nu}_{\mathrm{H}}=\mathrm{hH} / \mathrm{k} \quad$ Nusselt number based on channel height

$\mathrm{R}$

$\operatorname{Re}_{\mathrm{H}}=\rho \mathrm{UH} / \mu$

$\mathrm{t}$

$\mathrm{T}$

$\mathrm{T}_{\mathrm{i}}$

$T_{\infty}$

$\mathrm{U}$

W

$\mathrm{X}$

$\mathrm{Z}$

$\alpha$

$\gamma=\frac{h \sqrt{t}}{\sqrt{\rho c k}}$

$\theta=\frac{T(0, t)-T_{i}}{T_{\infty}-T_{i}}$ nondimensional temperature difference

$\mu \quad$ air absolute viscosity, $\mathrm{N} \mathrm{s} / \mathrm{m}^{2}$

lexan thermal conductivity, W/m K test section length, $\mathrm{cm}$

air mass flow rate, $\mathrm{kg} / \mathrm{s}$

cylinder radius, $\mathrm{cm}$

Reynolds number based on channel height

time, s

temperature, $\mathrm{K}$

initial temperature, $\mathrm{K}$

flow mean temperature, $\mathrm{K}$

mean flow velocity, $\mathrm{m} / \mathrm{s}$

channel width, cm

test section axial coordinate, or semi-infinite solid depth coordinate, $\mathrm{cm}$

test section spanwise coordinate

lexan thermal diffusivity, $\mathrm{m}^{2} / \mathrm{s}$

nondimensional heat transfer coefficient

\section{APPARATUS}

The experiments were performed in a narrow rectangular duct designed to simulate a single passage of a fin-tube heat 


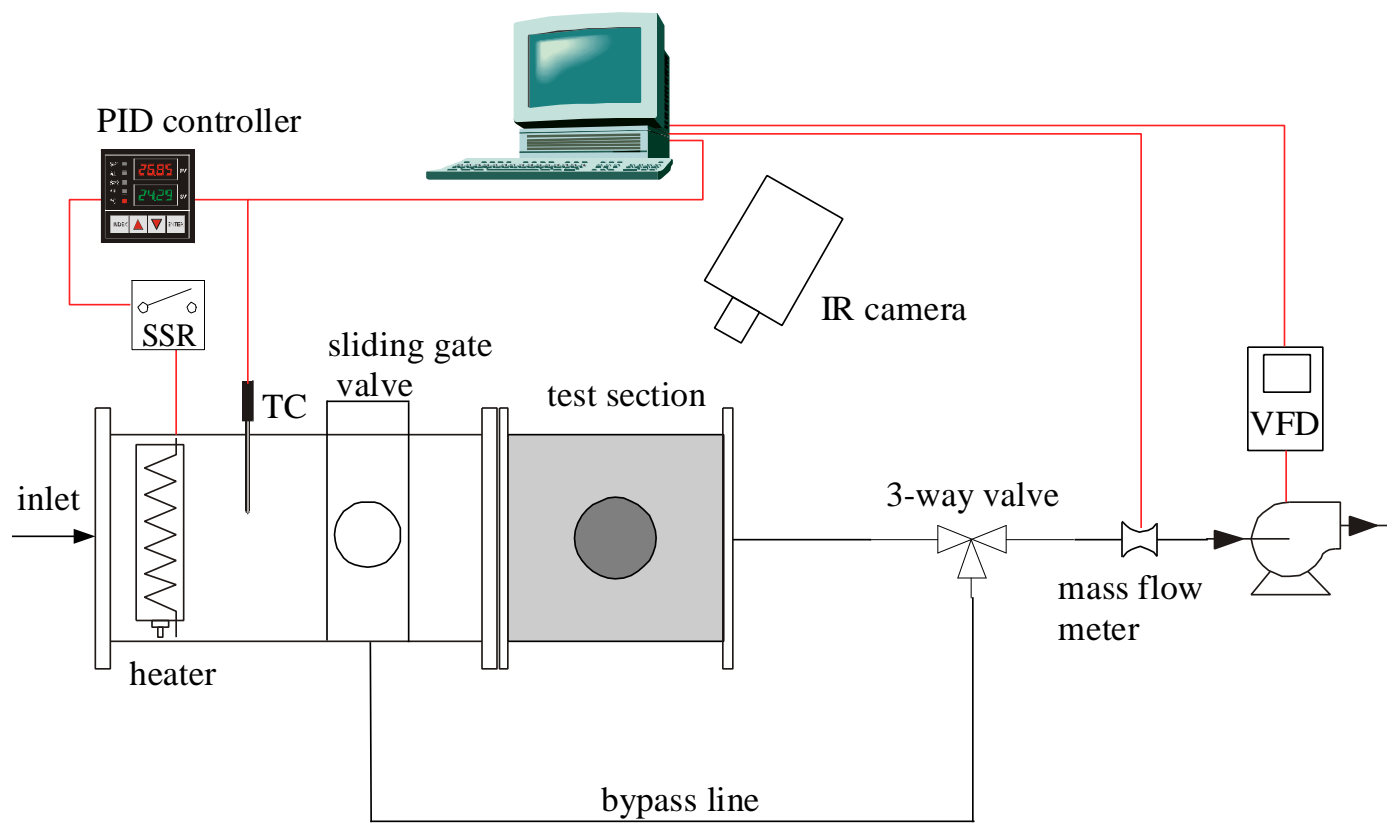

Figure 2. Schematic of flow loop.

exchanger. A drawing of the test section is shown in Fig. 1. Dimensions of the flow channel were width, $\mathrm{W}=11.4 \mathrm{~cm}$, height, $\mathrm{H}=1.0 \mathrm{~cm}$ (4.5 in $\mathrm{x} 0.4 \mathrm{in}$ ). It is scaled up to approximately double-size compared to a typical fin-tube condenser heat exchanger. The duct was fabricated primarily out of lexan polycarbonate. For the circular-tube tests, a 5.08$\mathrm{cm}$ (2.0 in) diameter circular disk, representing the tube of a fin-tube heat exchanger, also fabricated from lexan, was positioned in the center of the duct as shown. The test section length was $27.94 \mathrm{~cm}$ (11.0 in.), yielding $\mathrm{L} / \mathrm{H}=27.5$. A flowdevelopment section with $\mathrm{L} / \mathrm{H}=30$ was located upstream of the test section. Consequently, depending on Reynolds number, the flow is approximately hydrodynamically fully developed as it enters the test section.

In order to enable thermal visualization of the test section bottom surface (representing the fin surface), the top wall of the flow duct in the vicinity of the circular tube was formed by calcium fluoride $\left(\mathrm{CaF}_{2}\right)$ windows. Initial testing (single circular tube, delta-winglet pair) was performed using two $\mathrm{CaF}_{2}$ windows, each $12.7 \mathrm{~cm} \times 6.35 \mathrm{~cm} \times 6 \mathrm{~mm}(5$ in. $x 2.5 \mathrm{in}$. $\mathrm{x} 0.24$ in.). Subsequent testing with the circular tube plus winglets was performed using a single larger window, $12.7 \mathrm{~cm}$ x $12.7 \mathrm{~cm}$ x $6 \mathrm{~mm}$ (5 in. $\mathrm{x} 5$ in. $\mathrm{x} 0.24$ in.). The $\mathrm{CaF}_{2}$ windows enabled viewing of test section bottom surface with an imaging infrared camera. Lexan is opaque in the sensitive wavelength range of the camera (3.6 to $5 \mu \mathrm{m})$. The transmissivity of the $\mathrm{CaF}_{2}$ windows is very high (>95\%) in this wavelength range. The test section bottom surface (polycarbonate) was painted black using ultra-flat black paint in order to achieve a surface emissivity very close to 1.0. This emissivity value was verified over a wide temperature range in separate camera-calibration tests by comparing cameraindicated temperatures with surface temperatures measured using a precision thin-foil flush-mounted thermocouple bonded to a black-painted polycarbonate test surface. Therefore no emissivity corrections were required for the infrared temperature measurements.

A transient heat transfer measurement technique was employed for obtaining detailed local heat transfer measurements on the model fin surface. A schematic of the flow loop is shown in Figure 2. Inlet air is heated to a desired setpoint temperature using an in-line feedback-controlled finned-element air heater $(350 \mathrm{~W})$. The heated air initially flows through a bypass line until the desired air temperature and flow rate is established. The air is then suddenly diverted through the test section by changing the position of a 3-way valve. Using this technique, the room-temperature fin/tube model is suddenly exposed to a uniformly heated airflow, thereby inducing a heat conduction transient in the lexan substrate. Local surface temperatures on the substrate increase at a rate that is dependent on the value of the local heat transfer coefficient. This transient localized heating is quantitatively recorded using an imaging infrared camera. Values of local heat transfer coefficients can then be determined from an inverse heat conduction analysis.

The bypass flow is diverted from the main flow duct through a circular hole $(4.85 \mathrm{~cm}$ diameter) cut into the bottom of the flow-development section. The center of the hole is located $8.25 \mathrm{~cm}$ (3.25 in.) upstream of the test section entrance. The duct walls downstream of this location are not preheated during the flow establishment period. Therefore this distance represents a thermal entry length. When flow is suddenly initiated through the test section by changing the position of the 3-way valve, the flow bypass hole in the bottom of the flow development section is covered by sliding a flat lexan cover (sliding gate valve) over the hole. This procedure provides a continuous flat smooth flow surface, eliminating any concerns about a cavity-type flow disturbance associated with the hole. 


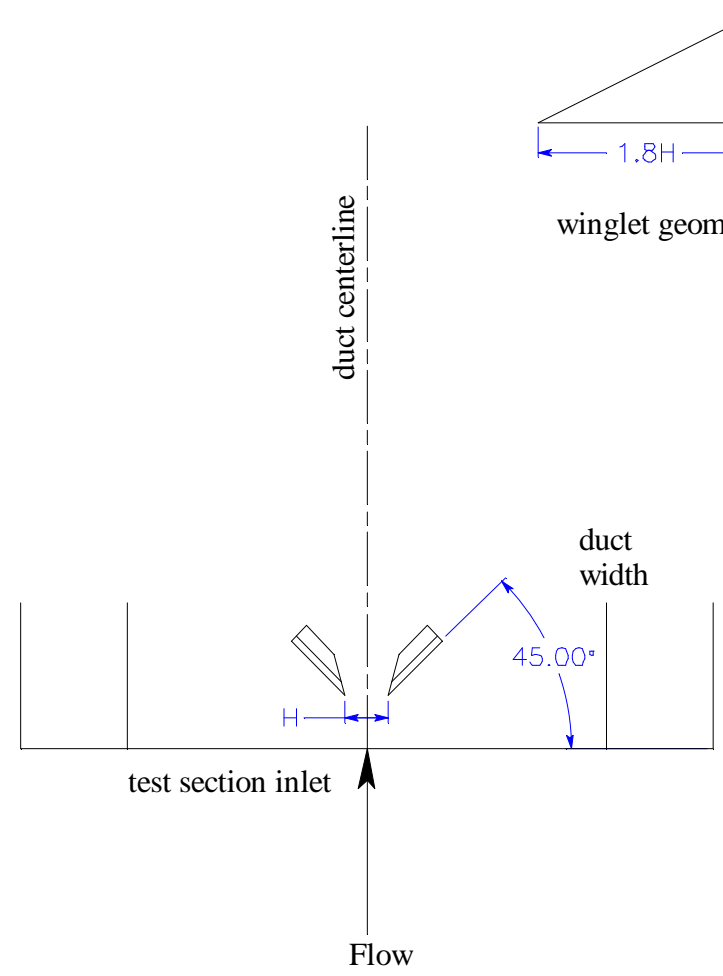

(a)

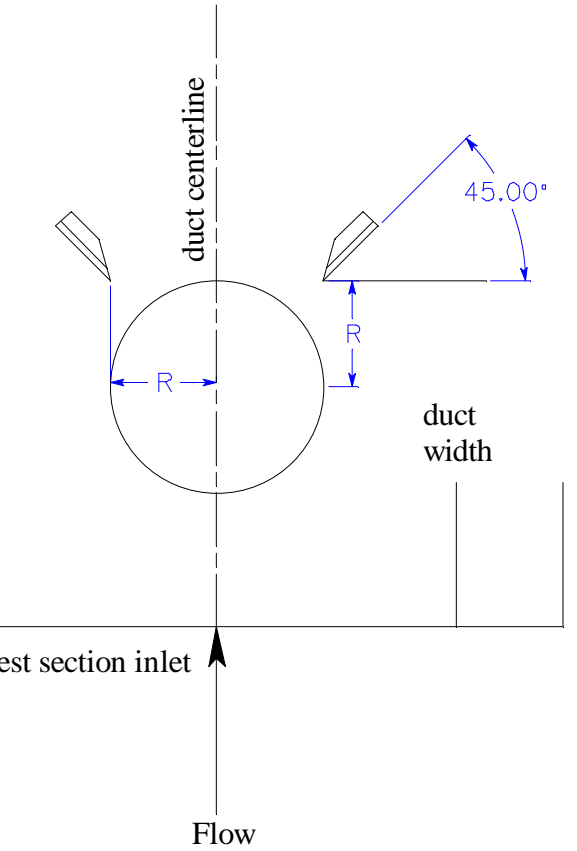

(b)

Figure 3. Winglet locations and geometry; (a) winglet-only case, (b) circular cylinder plus winglets

Heater control is accomplished using a PID controller (Yokogawa Model 514) coupled to a solid-state relay with a pulsed relay output. A thermocouple mounted inside the duct measures the process variable. Air temperature uniformity across the duct was verified via infrared imaging of the test surface during preliminary tests with no test cylinder in place. Airflow rate is monitored through the use of an in-line precision mass-flow meter (Kurz model 504FT) plumbed into the exhaust line. Test-section mass-average velocities and Reynolds numbers were calculated based on the SCMH values obtained from the mass-flow meter. Air is drawn through the system by a centrifugal blower (1/3 HP, $240 \mathrm{~V} 3$-phase) located at the flow exit. Blower speed is controlled by a sub-micro inverter variable-frequency drive (AC Tech model SF215), which in turn is controlled by a computer-generated 4-20 mA control signal. System flow rate varies linearly with blower speed over the range used in this study from about $1.51 \times 10^{-3}$ to $14.0 \times 10^{-3} \mathrm{~kg} / \mathrm{s}$. These flow rates correspond to a ductheight Reynolds number $\left(\operatorname{Re}_{\mathrm{H}}=\rho \mathrm{UH} / \mu=\dot{m} / \mu \mathrm{W}\right)$ range of $670-6300$ with a duct height of $1.106 \mathrm{~cm}$ and a duct widthto-height ratio, W/H, of 11.25 .

Two flush-mounted thin-foil thermocouples were bonded to the bottom surface of the test section near the test section inlet. These thermocouples provide a continuous indication of surface temperature at two locations and are used to help determine the exact start time of each test, which occurs when the heated airflow is diverted through the test section.

Heat transfer results will be presented for three experimental configurations: circular tube, delta-winglet pair, and circular tube plus delta-winglet pair. The test section geometry for the circular tube was presented in Figure 1. The specific geometries for the delta-winglet pair and the circular tube plus delta-winglet pair are presented in Fig. 3. The winglets had a 1:2 height/length aspect ratio and were oriented at a 45 degree angle to the flow. The height of the winglets was $90 \%$ of the channel height. This height was chosen rather than the full channel height in order to avoid damage to the $\mathrm{CaF}_{2}$ windows. The winglets were machined from lexan polycarbonate and were bonded to the test surface. The test configuration for the winglet-only tests is shown in Fig. 3 (a). For these tests, the winglets were located near the test section inlet and were spaced one channel height apart. The test configuration for the circular tube plus delta-winglet pair tests is shown in Fig. 3 (b). The location of the winglets for these tests was based on the geometry recommended in reference [4]. The winglet tips are located downstream of the test cylinder at the intersection of the horizontal and vertical cylindrical-tube tangent lines. The angular orientation with respect to the flow was again 45 degrees.

Quantitative thermal visualization images are obtained using a precision imaging infrared camera (FLIR PRISM DS). This camera uses a fully calibrated $320 \times 244$ platinum-silicide IR CCD focal plane array detector which operates at a temperature of $77 \mathrm{~K}$. The detector temperature is maintained by a mechanical split-stirling-cycle helium cryo-cooler. In its base mode of operation, the camera can be used to measure infra-red intensities corresponding to temperatures in the -10 to $250^{\circ} \mathrm{C}$ range, with extended ranges available through the 
use of filters up to $1500^{\circ} \mathrm{C}$. The camera detector has a 12-bit digital dynamic range and a minimum discernible temperature difference (MDT) of $0.1^{\circ} \mathrm{C}$ at $30^{\circ} \mathrm{C}$. It is equipped with a 25 $\mathrm{mm}$ standard lens, which provides a $17^{\circ} \times 13^{\circ}$ field of view. All radiometric information is stored in binary digital files on PCMCIA flash memory cards for subsequent analysis. Infrared thermography has several advantages over thermochromic liquid crystals for surface temperature mapping, including wide available temperature range, high spatial resolution, excellent thermal resolution, and full-field direct digital data acquisition and processing.

The thermal image binary data files created by the camera onboard processor are stored in a specialized 16-bit TIFF grayscale format (file extension .ana). These files include not only the image pixel values, but also a large amount of camera and test-specific information such as camera and firmware identifiers, date and time of image acquisition, camera settings at image acquisition, and temperature/pixel calibration data points. This information is included in the TIFF file in the form of "private tags" [8]. Specific file-format information provided by FLIR was used in conjunction with general information about the TIFF standard found in reference [8] to fully decode the binary data files for subsequent thermal analysis using a Labview program created for this purpose.

Signals from loop instrumentation were fed into a modular multiplexing data-acquisition system (Hewlett Packard 3852A) which in turn was interfaced to a system-controller computer via an IEEE-488 bus. For this experiment, the data acquisition unit was configured with a 20-channel FET multiplexer with thermocouple compensation, a 5 1/2 digit integrating voltmeter, and a 4-channel voltage/current DAC. The DAC module was used to provide control signals $(4-20 \mathrm{~mA})$ to the variable-frequency blower drive. The mass-flow meter was configured to communicate directly with the computer using an RS-232 interface. Data-acquisition and instrument-control system programming was accomplished using Labview (National Instruments Version 5.1) software. The data files included time histories of the thermocouple and mass-flow meter signals with updates at 0.7 -second intervals.

\section{EXPERIMENTAL PROCEDURE}

As mentioned previously, a transient heat transfer technique was employed in order to obtain measurements of local heat transfer coefficients on model fin surfaces. Details of the experimental procedure will now be provided. After the IR camera is powered up and the detector array has reached its $77 \mathrm{~K}$ operating temperature, the camera is positioned above the test section at an appropriate height for observing either the entire portion of the test section or a close-up view. In order to avoid IR reflections of the warm camera body off the $\mathrm{CaF}_{2}$ windows, the camera is positioned at a small angle off the vertical. The camera gain and level adjustments are set such that the minimum observable temperature corresponds to the initial temperature with a temperature range of $10-15^{\circ} \mathrm{C}$.
The software clock on the camera is synchronized with the clock on the data acquisition computer to within $\pm 0.5 \mathrm{~s}$. The 3 -way valve is set to the bypass position and the sliding gate valve is opened. Flow is initiated through the bypass line by adjusting the blower RPM until the desired flow rate is observed. The air temperature is established by adjusting the PID controller set-point value to the desired level, typically $45^{\circ}$ C. Before diverting heated air through the test section, a pretest thermal image of the test section is acquired. At this time, the data acquisition system is set to begin writing data to disk. The 3-way valve position is then changed and the sliding gate valve is closed to divert the heated airflow through the test section, initiating the thermal transient. A number of thermal images of the test section (typically 5) are acquired during the first 5-60 seconds of the transient. These images are stored on PCMCIA flash memory cards and are transferred to the system controller computer after each test.

\section{DATA REDUCTION}

The objective of the tests is to obtain detailed maps of local heat transfer coefficient. The IR images provide local surface temperatures at specified times after initiation of the transient. In order to obtain heat transfer coefficients from the measured surface temperatures, the bottom surface of the test section is assumed to behave locally as a one-dimensional semi-infinite solid undergoing a step change in surface heat transfer coefficient. For the $1.27-\mathrm{cm}$ thickness of the lexan test surface, the semi-infinite assumption is valid for at least 88 seconds after initiation of the transient. The time-dependent surface (x $=0$ ) temperature for a semi-infinite solid subjected to this boundary condition is given by [9]:

$$
\frac{T(0, t)-T_{i}}{T_{\infty}-T_{i}}=1-\exp \left(\frac{h^{2} \alpha t}{k^{2}}\right) \operatorname{erfc}\left(\frac{h \sqrt{\alpha t}}{k}\right)
$$

and if we let

$$
\theta=\frac{T(0, t)-T_{i}}{T_{\infty}-T_{i}} ; \gamma=\frac{h \sqrt{\alpha t}}{k}=\frac{h \sqrt{t}}{\sqrt{\rho c k}}
$$

the equation reduces to

$$
\theta=1-\exp \left(\gamma^{2}\right) \operatorname{erfc}(\gamma)
$$

This equation represents the relationship between heat transfer coefficient and surface temperature measured at a specific time after the start of the test. It must be solved iteratively for $\gamma$. However, since the camera pixel array includes over 78000 pixels, it is not practical to directly solve the equation at every pixel. Instead, a look-up-table approach was used in the datareduction scheme. The measured temperature range for each thermal image is divided into 100 increments and a value of 
heat transfer coefficient is obtained for each of these 100 temperatures by iteratively solving equation (4). Each actual pixel temperature is then converted to a heat transfer coefficient by linear interpolation among the 100 increments.

\section{EXPERIMENTAL UNCERTAINTY}

Estimates of the experimental uncertainties of the Reynolds numbers and heat transfer coefficients presented in this paper have been obtained based on constant-odds, 95\% confidence level [10]. For Reynolds number, the uncertainties associated with the mass-flow meter and the viscosity need to be considered. The accuracy specification for the mass-flow meter was stated by the manufacturer (and independently verified at the INEEL calibration laboratory) as $\pm 2 \%$ of reading plus $0.5 \%$ of full scale. The uncertainty in the viscosity is very small, since it is calculated quite accurately for each run at the measured duct air temperature as part of the data reduction procedure. Total relative uncertainty in Reynolds number was estimated to be about $9 \%$ at $\mathrm{ReH}=670$ and $2.5 \%$ at $\mathrm{ReH}=6300$. For the heat transfer coefficients, individual uncertainties in imagecapture time, surface temperature, air temperature, and substrate thermal product were considered. Results indicated that the relative uncertainty in heat transfer coefficient ranges from $20 \%$ at $\mathrm{h} \sim 10 \mathrm{~W} / \mathrm{m}^{2} \mathrm{~K}$ to $10 \%$ at $\mathrm{h} \sim 120$ $\mathrm{W} / \mathrm{m}^{2} \mathrm{~K}$.

\section{RESULTS}

Local surface heat transfer contour plots for the delta-winglet-pair configuration are presented in Fig. 4. Heat transfer results are presented as a function of Reynolds number based on channel height, $H$. Heat transfer coefficients are based on the test section inlet temperature. The results presented in Fig. 4 reveal the heat transfer effects of a double-vortex system associated with each winglet [3]. The vortices are swept downstream as longitudinal vortices. The main vortex, located directly downstream of the vortex generators, is formed by flow separation along the leading edge of the winglets. The corner vortex, located outside of the main vortex, develops like a horseshoe vortex on the upstream-facing pressure side of the winglets. The heat transfer effects of the vortices persist for many channel heights (at least 15) downstream of the winglet location. The horizontal line near the center of each heat transfer distribution is an artifact caused by the boundary between two of the $\mathrm{CaF}_{2}$ windows. The small circular white region in the center of each image just below the horizontal window boundary is a bolt hole used to attach a circular disk for the fin/tube studies to be discussed later in this paper. This hole was covered with tape on the outside substrate surface to avoid any flow disturbance. Apparent heat transfer coefficient
$\mathrm{Re}_{\mathrm{H}}=\mathbf{1 1 5 0}$

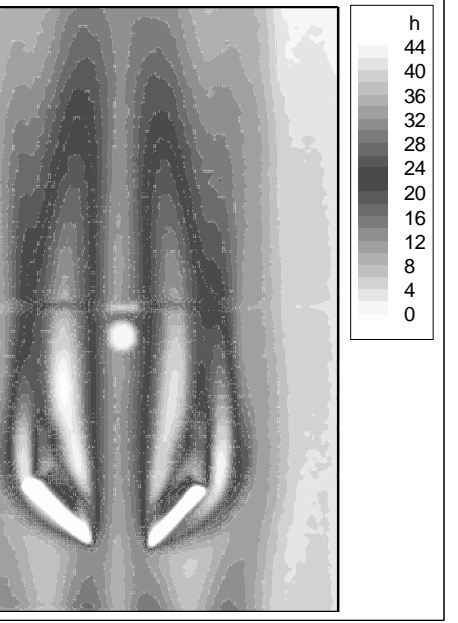

$\mathbf{R e}_{\mathrm{H}}=\mathbf{3 5 2 0}$

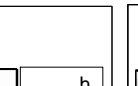

$$
\mathrm{Re}_{\mathrm{H}}=\mathbf{3 5 2 0}
$$
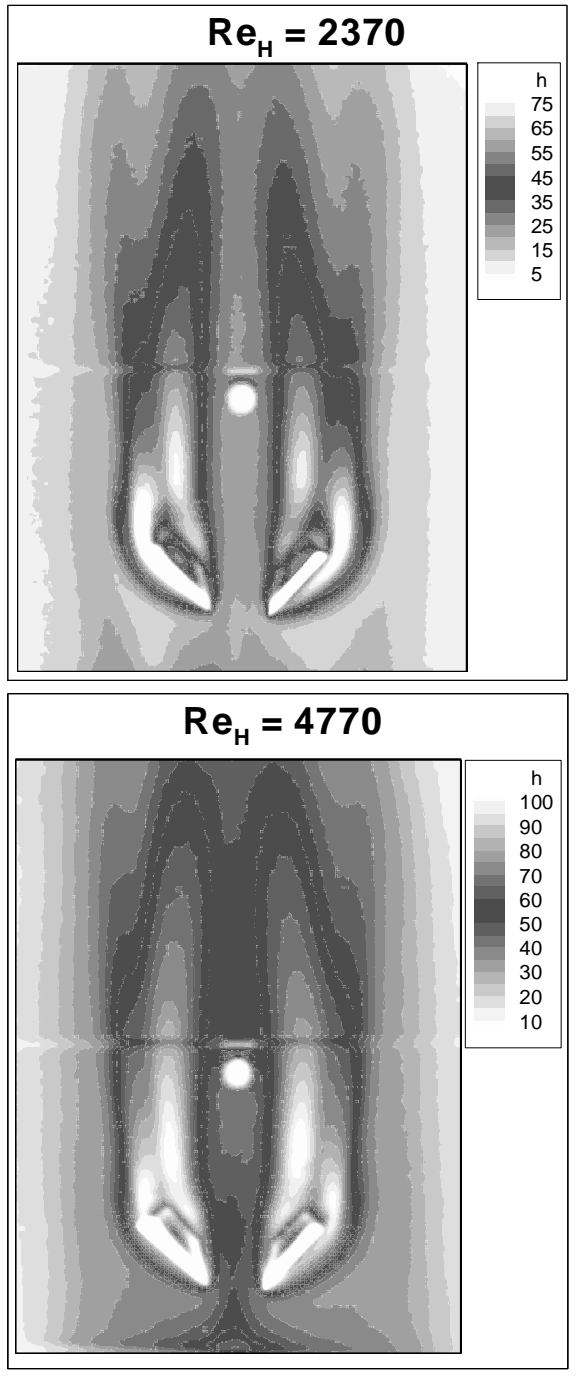

Figure 4. Local fin-surface heat transfer coefficients for a delta-winglet pair.

values on the winglets themselves are not valid since the onedimensional semi-infinite assumption does not apply at this location.

At low Reynolds numbers, maximum fin-surface heat transfer coefficients are observed in the main vortex downstream of the winglets. At higher Reynolds numbers, maximum values are associated with the corner vortex, very close to the outer corner of the winglets. The magnitudes of these peak values are similar to the peak values observed in the same duct in the stagnation region of a circular cylinder, as reported in [7]. The peak values are about $4-5$ times larger than corresponding fully developed duct values. However, mean surface heat transfer coefficient values for the configuration displayed in Fig. 4 are just about equal to the corresponding fully developed duct values, as predicted using the Dittus-Boelter correlation, with Reynolds number based on the hydraulic diameter of the rectangular duct. The individual vortices appear to be most well defined at the lowest Reynolds number shown. Lowest 

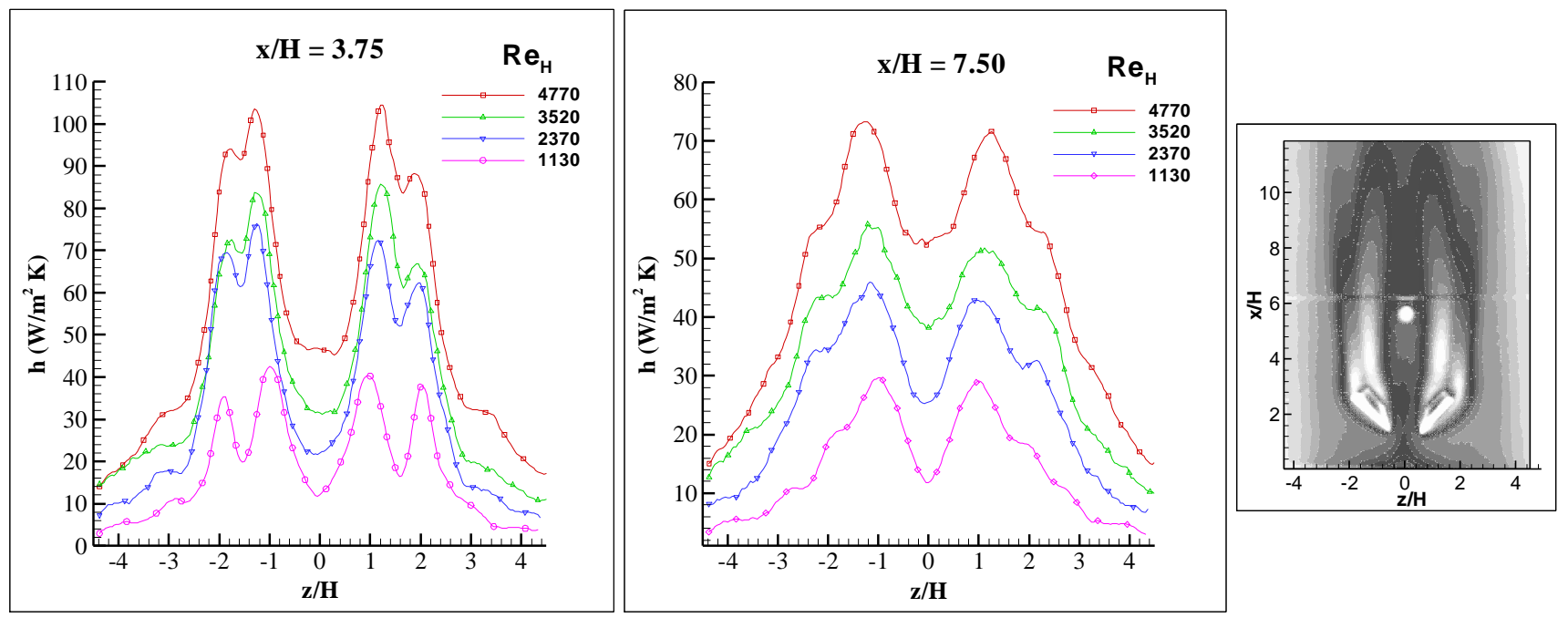

Figure 5. Spanwise variation of local heat transfer coefficient for delta-winglet-pair configuration.

heat transfer coefficients occur in the corner regions of the rectangular duct, which are at the sides of the images shown in Fig. 4.

The spanwise variation in local finsurface heat transfer coefficient for the delta-winglet-pair configuration is presented in Fig. 5 at two different axial measurement locations. The coordinate system used is defined in the figure. These plots clearly show the heat transfer effects of the winglet-induced doublevortex system. The local spanwise variation in heat transfer coefficient at $\mathrm{x} / \mathrm{H}=3.75$, which is just downstream of the winglets, shows very sharp double peaks in local heat transfer associated with each vortex generator. For all of the Reynolds numbers shown, the highest heat transfer coefficients at each axial location are associated with the primary vortex. The magnitude of the local heat transfer coefficient decreases sharply from the peak values to a minimum near the sides of the rectangular duct. At $\mathrm{y} / \mathrm{H}=7.50$, the spanwise heat transfer variations are broader, and the peak associated with the corner vortex is visible, but indistinct.

The second configuration considered for this study was the case of a circular cylinder plus winglets (see Fig. 3 for geometry specifics). Local fin-surface heat transfer results for this configuration are presented in Fig. 6 for four Reynolds numbers. The addition of winglets yields
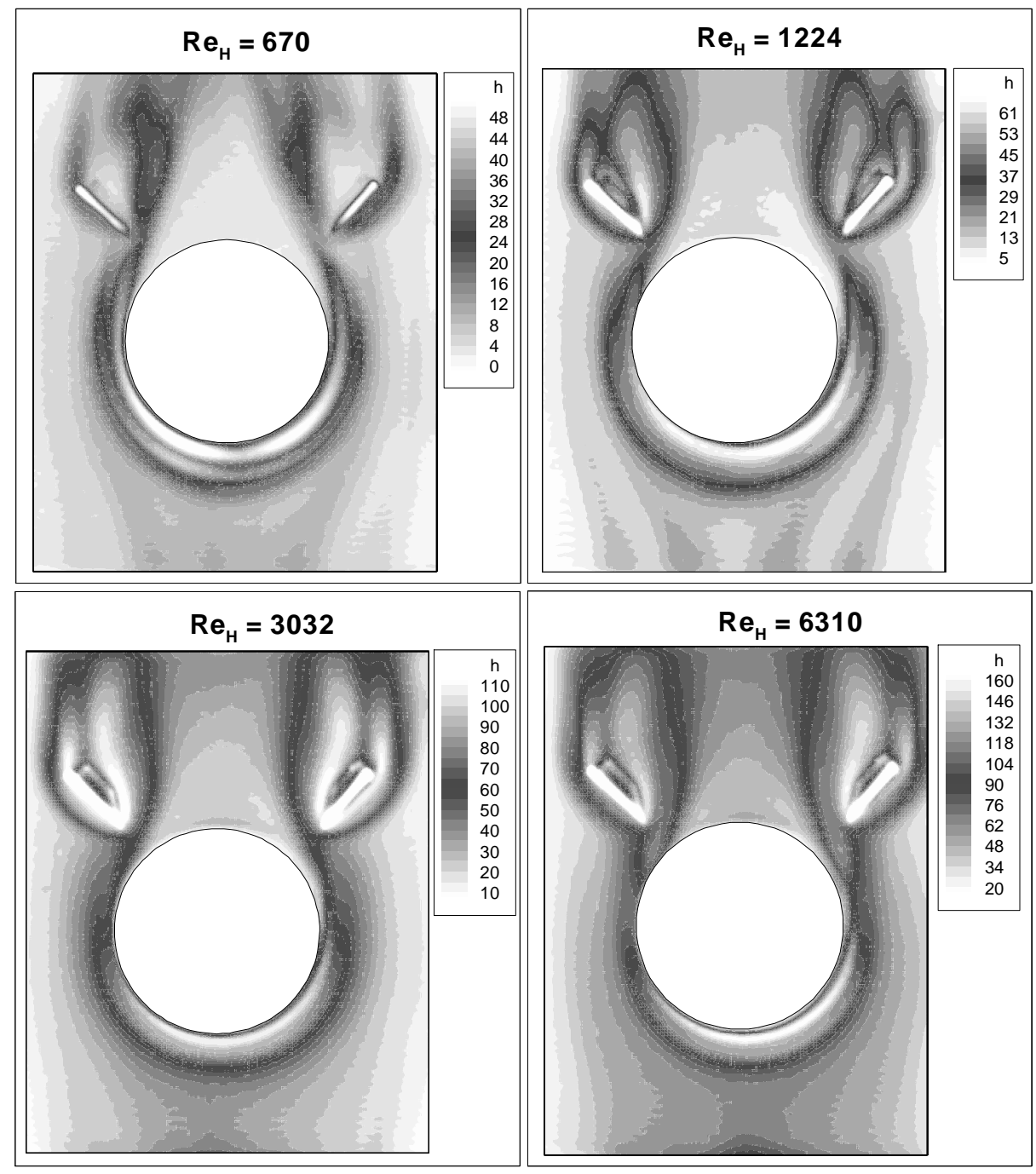

Figure 6. Local fin-surface heat transfer distributions for circular cylinder plus winglets. 


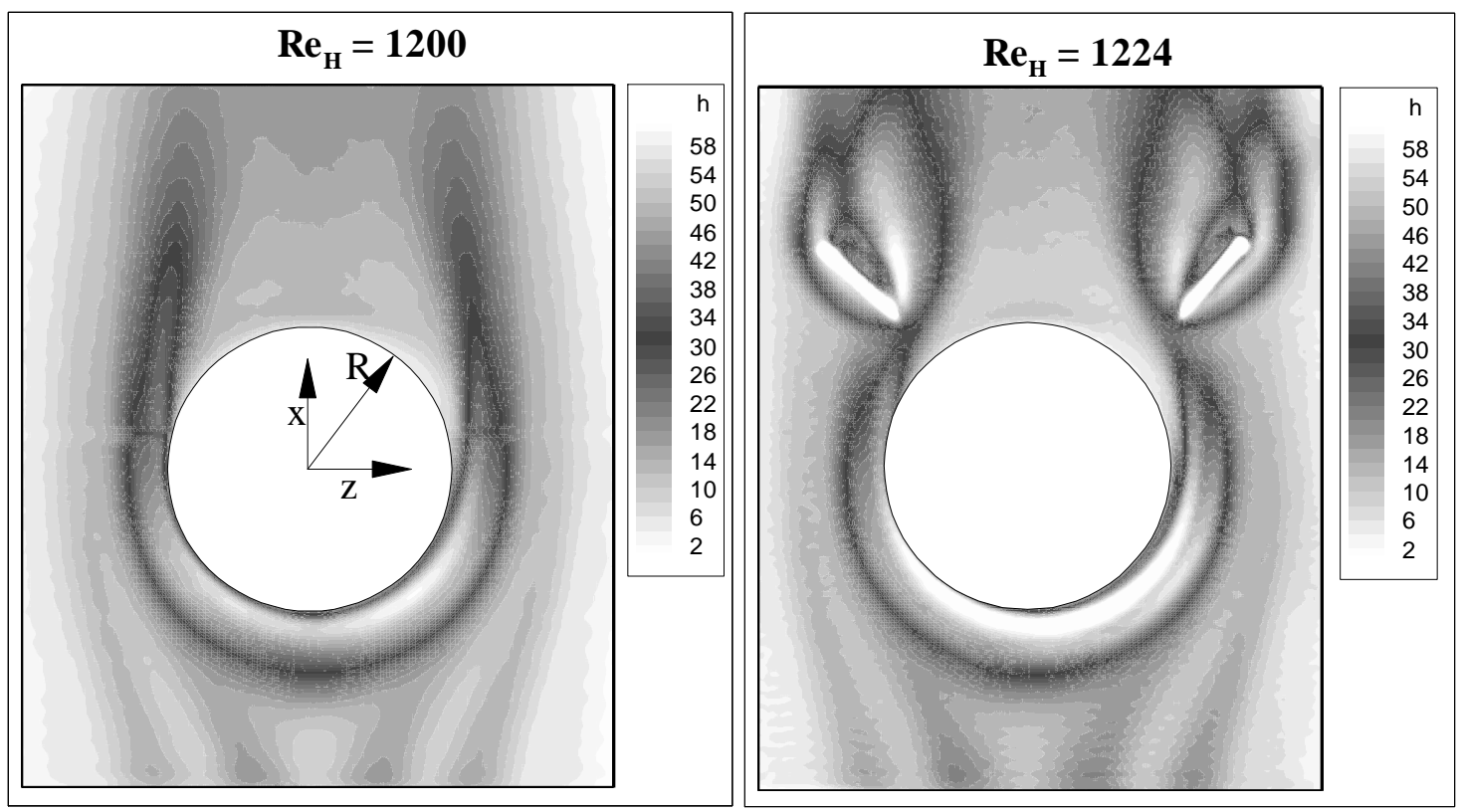

Figure 7. Direct comparison of local heat transfer distributions for a circular cylinder with and without winglets.

a reduction in the size of the low-heat-transfer wake region and also provides localized heat transfer enhancement in the vicinity of the winglets similar in magnitude to the localized enhancement observed for the delta-winglet-pair cases shown in Fig. 4. With the exception of the lowest Reynolds number case, peak local heat transfer coefficients in the vicinity of the winglets are similar to the peak values observed in the cylinder stagnation region. A distinct double peak in local heat transfer coefficient can be seen in the cylinder stagnation region at $\mathrm{ReH}$ $=670$. This double peak was discussed in some detail in reference [7] for a cylinder without winglets. The spanwise streaks evident near the test section inlet for $\operatorname{Re}=1224$ are associated with secondary flows that become established in the flow development section of the rectangular duct.

A direct comparison of local heat transfer distributions for a circular cylinder with and without winglets at $\mathrm{Re}_{\mathrm{H}} \sim 1200$ is presented in Fig. 7. The comparison reveals that, for this winglet location, the horseshoe vortex produced by the interaction of the flow with the circular cylinder is disrupted by the winglets. There is a reduction in the width of the low-heattransfer wake region, but the heat transfer coefficients directly downstream of the cylinder are actually slightly reduced for the winglet case compared to the no-winglet case. Stagnationregion heat transfer coefficients are slightly higher for the winglet case compared to the no-winglet case.

A plot of the spanwise variation in local wake-region heat transfer coefficient at an axial location just downstream of the winglets is presented in Fig. 8 for the same two data sets presented in Fig. 7. The spanwise variation for the winglet case clearly shows a double peak associated with each winglet. A single peak associated with each horseshoe vortex is evident in the no-winglet curve.
Overall mean fin-surface Nusselt numbers calculated from the heat-transfer-coefficient data files are presented in Fig. 9. For calculation of mean Nusselt numbers, the regions occupied by the winglets and the cylinder (if applicable) were not included. The characteristic dimension used here for both the Reynolds number and the Nusselt number is the channel height, H. This

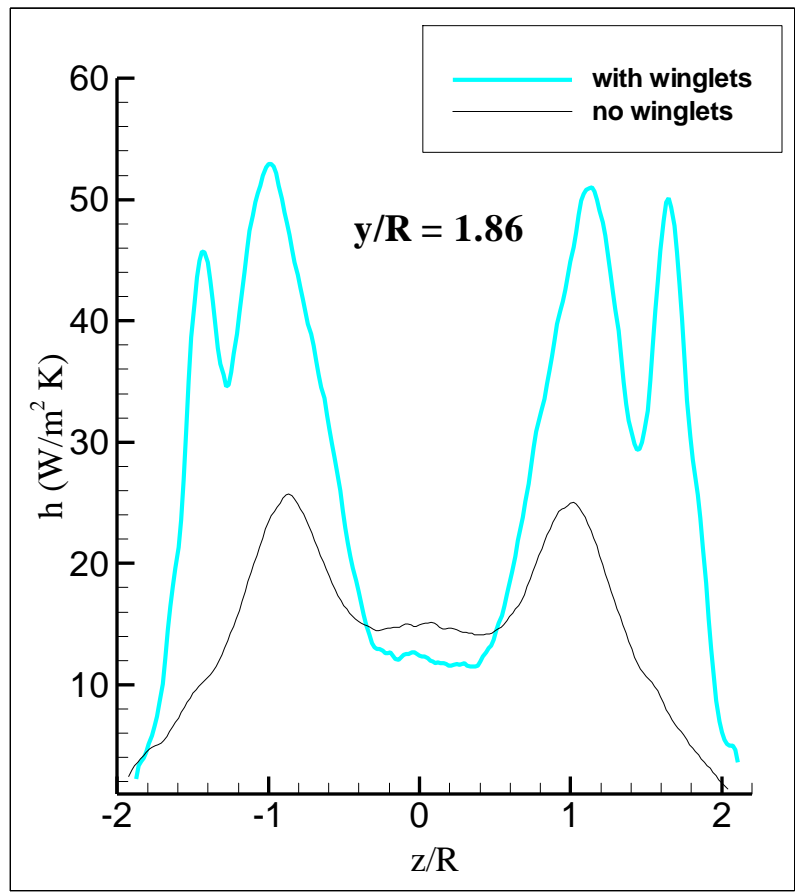

Figure 8. Spanwise variation in local wake-region heat transfer coefficient, with and without winglets, $\mathrm{Re}_{\mathrm{H}}=1200$. 
characteristic dimension was chosen for consistency with previous related literature [1-6]. Results from three configurations are included in the figure: delta-winglet pair (no cylinder), circular cylinder without winglets, and circular cylinder with winglets. In addition, a curve representing the Dittus-Boelter correlation for turbulent duct flow is included. Per accepted practice [9], the Dittus-Boelter results were calculated using the duct hydraulic diameter as the characteristic dimension. The Reynolds and Nusselt numbers were then converted to the form based on the duct height, $\mathrm{H}$. It should be noted that since the hydraulic diameter for this duct is almost twice the duct height, transition to turbulence would be expected to occur at an $\mathrm{Re}_{\mathrm{H}}$ value of approximately 1250 .

Results presented in Fig. 9 indicate a significant level of heat transfer enhancement associated with the deployment of the winglets with the circular cylinder. At the lowest Reynolds numbers (which correspond to the laminar operating conditions of existing geothermal air-cooled condensers), the enhancement level is nearly a factor of two. At higher Reynolds numbers, the enhancement level is close to $50 \%$. Mean Nusselt numbers for the cylinder-only case and the winglet-only case were very similar to each other and very close to the Dittus-Boelter correlation. The agreement with Dittus-Boelter is surprising since this correlation applies to fully-developed turbulent pipe (or duct) flow without any protuberances in the flow. Low heat transfer coefficient values in the corner regions of the duct were included in the calculation of the mean values. Also, when the cylinder is in place, high stagnation-region local heat transfer is offset by the low wake-region values.

A complete evaluation of the usefulness of the addition of winglets to the fin surfaces in a actual heat exchanger must account for the increase in pressure drop associated with the winglets. Work is currently under way on obtaining these measurements.

\section{SUMMARY AND CONCLUSIONS}

An experimental study has been performed on local heat transfer in a narrow rectangular duct fitted with a circular tube, and/or winglet vortex generators. The duct was designed to simulate a single passage in a fin-tube heat exchanger with a duct height of $1.106 \mathrm{~cm}$ and a duct width-to-height ratio, $\mathrm{W} / \mathrm{H}$, of 11.25. The test section length yielded $\mathrm{L} / \mathrm{H}=27.5$ with a flow development length of $\mathrm{L} / \mathrm{H}=30$. The test cylinder was sized to provide a diameter-to-duct height ratio, $\mathrm{D} / \mathrm{H}$ of 5 .

Heat transfer measurements were obtained using a transient technique in which a heated airflow was suddenly introduced to the ambient-temperature test section. High-resolution local test-surface temperature distributions were obtained at several times after initiation of the transient using an imaging infrared camera. Corresponding local fin-surface heat transfer coefficient distributions were calculated from a locally applied

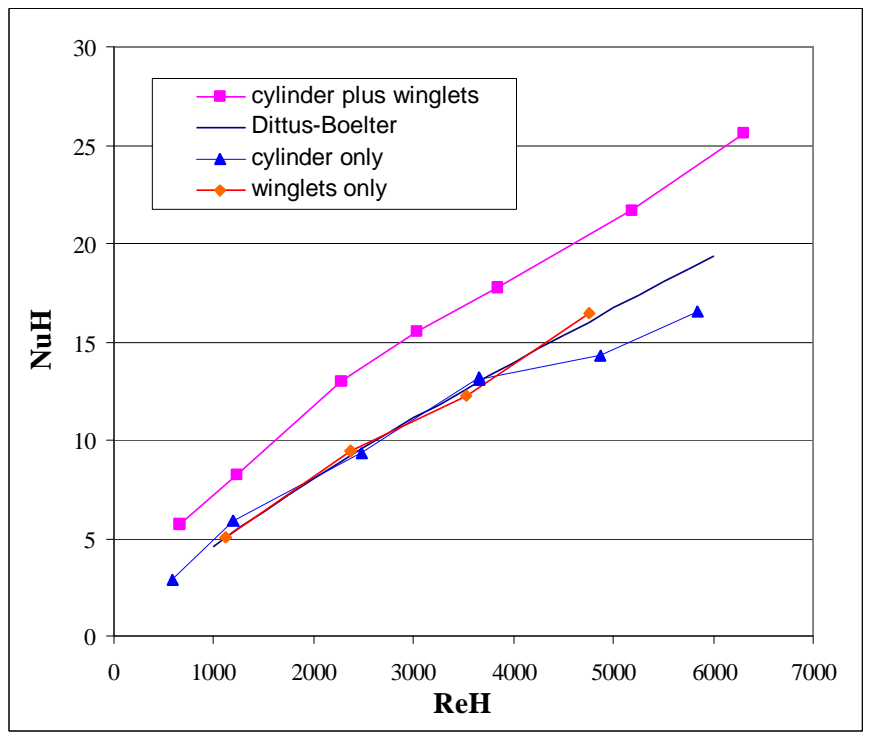

Figure 9. Mean Nusselt numbers.

one-dimensional semi-infinite inverse heat conduction model. Heat transfer results were obtained over an airflow rate ranging from $1.51 \times 10^{-3}$ to $14.0 \times 10^{-3} \mathrm{~kg} / \mathrm{s}$. These flow rates correspond to a duct-height Reynolds number range of $670-$ 6300.

Local heat transfer distributions observed for the case of a delta-winglet pair with no tube show the effects of a doublevortex system associated with each winglet. Peak vortexinduced heat transfer coefficients are about $4-5$ times larger than corresponding fully developed duct values. However, mean surface heat transfer coefficient values for the deltawinglet pair configuration are just about equal to the corresponding fully developed duct values, as predicted using the Dittus-Boelter correlation, with Reynolds number based on the hydraulic diameter of the rectangular duct. The local spanwise variation in heat transfer coefficient at $\mathrm{x} / \mathrm{H}=3.75$, which is just downstream of the winglets, shows very sharp double peaks in local heat transfer associated with each vortex generator. For all of the Reynolds numbers shown, the highest heat transfer coefficients at each axial location are associated with the primary vortex.

Heat transfer results for the circular-cylinder-plus-winglets configuration indicate that the addition of winglets yields a reduction in the size of the low-heat-transfer wake region and also provides localized heat transfer enhancement in the vicinity of the winglets similar in magnitude to the localized enhancement observed for the delta-winglet-pair-only cases. With the exception of the lowest Reynolds number case, peak local heat transfer coefficients in the vicinity of the winglets are similar to the peak values observed in the cylinder stagnation region.

Overall mean fin-surface Nusselt numbers indicate a significant level of heat transfer enhancement associated with 
the deployment of the winglets with the circular cylinder. At the lowest Reynolds numbers (which correspond to the laminar operating conditions of existing geothermal air-cooled condensers), the enhancement level is nearly a factor of two. At higher Reynolds numbers, the enhancement level is close to $50 \%$. Mean Nusselt numbers for the cylinder-only case and the winglet-only case were very similar to each other and very close to the Dittus-Boelter correlation.

\section{ACKNOWLEDGMENTS}

This work was sponsored by the U.S. Department of Energy, Geothermal Program. The Idaho National Engineering and Environmental Laboratory is operated by Bechtel, Babcock and Wilcox Idaho, LLC under contract number DE-AC0799ID13727.

\section{REFERENCES}

1. Jacobi, A. M., and Shah, R. K., "Heat Transfer Surface Enhancement through the Use of Longitudinal Vortices: A Review of Recent Progress," Experimental Thermal and Fluid Science, Vol. 11, pp. 295-309, 1995.

2. Tiggelbeck, S., Mitra, N. K., and Fiebig, M., "Experimental Investigations of Heat Transfer Enhancement and Flow Losses in a Channel with Double Rows of Longitudinal Vortex Generators," Int. J. Heat Mass Transfer, Vol. 36, No. 9, pp. 2327-2337, 1993.

3. Torii, K., Nishino, K., and Nakayama, K., "Mechanism of Heat Transfer Augmentation by Longitudinal Vortices in a Flat Plate Boundary Layer," Proc. Tenth Int. Heat Transfer Conf., Vol. 6, pp. 123-128, Hemisphere, New York, 1994.

4. Fiebig, M., Valencia, A., and Mitra, N. K., "Wing-Type Vortex Generators for Fin-and-Tube Heat Exchangers," Experimental Thermal Fluid Science, Vol. 7, pp. 287-296, 1993.

5. Chen, Y., Fiebig, M., and Mitra, N. K., "Conjugate Heat Transfer of a Finned Oval Tube Part B: Heat Transfer Behaviors," Numerical Heat Transfer, Part A, Vol. 33, pp. 387-401, 1998.

6. Chen, Y., Fiebig, M., and Mitra, N. K., "Heat Transfer Enhancement of a Finned Oval Tube with Punched Longitudinal Vortex Generators In-line," Intl. Journal of Heat and Mass Transfer, Vol. 41, pp. 4151-4166, 1998.

7. O'Brien, J. E., and Sohal, M. S., "Local Heat Transfer for Finned-Tube Heat Exchangers using Oval Tubes," Proceedings, 2000 ASME National Heat Transfer Conference, Pittsburgh, August, 2000, paper no. NHTC2000-12093.

8. Carlsen, S., "TIFF revision 6.0," Aldus Developers Desk (http://icib.igd.fhg.de/icib/it/defacto/company/aldus/read.h tml\#SEC_2), Aldus Corporation, 1992
9. Incropera, F. P., and DeWitt, D. P., Fundamentals of Heat and Mass Transfer, $3^{\text {rd }}$ edition, John Wiley and Sons, New York, 1990.

10. Moffatt, R. J., "Contributions to the Theory of SingleSample Uncertainty Analysis," Journal of Fluids Engineering, Vol. 104, pp. 250-260, 1982. 